\title{
ENTRE A EXIGÊNCIA DE QUALIDADE NO TRABALHO PEDAGÓGICO E A INCLUSÃO DE ALUNOS COM DEFICIÊNCIA NO ENSINO MÉDIO E NA UNIVERSIDADE
}

\author{
ENTRE LA EXIGENCIA DE CALIDAD EN EL TRABAJO PEDAGÓGICO Y LA \\ INCLUSIÓN DE ALUMNOS CON DISCAPACIDAD EN LA ENSEÑANZA \\ MEDIANA Y EN LA UNIVERSIDAD
}

\section{BETWEEN THE REQUIREMENT OF QUALITY IN PEDAGOGICAL WORK AND THE INCLUSION OF DISABLED STUDENTS IN MIDDLE SCHOOL AND UNIVERSITY}

\author{
Manoel Pinéo de SOUSA ${ }^{1}$ \\ Maria Socorro Lucena LIMA ${ }^{2}$ \\ Regiane Rodrigues ARAÚJO 3
}

RESUMO: O texto apresenta uma reflexão sobre os processos inclusivos na Educação Escolar e na Universidade. Uma questão orienta a pesquisa: como é feito a inclusão de alunos no Ensino Médio e na Universidade? Partindo da complexidade do contexto social, diante da proposta da educação de qualidade para todos, o texto tem como 3objetivos levantar o debate sobre as possibilidades e limites da educação de qualidade para todos, fazer uma revisão técnica que de subsídios para a discussão e refletir sobre o trabalho dos professores da Educação Básica e da Universidade diante dos alunos com deficiências nas salas de aula. Para tanto, tivemos como recurso metodológico a pesquisa bibliográfica e documental e diálogo com os professores. Com a utilização de autores como: Carneiro (2013), Magalhães (2002), Minayo (2010), Pimenta (2014), Mantoan (2006), Dorziat (2011), entre outros, o texto aponta para a necessidade de efetivação das políticas de inclusão e principalmente das condições objetivas de trabalho e formação. É preciso incentivo na pesquisa e nos processos formativos para a efetivação das políticas de inclusão.

PALAVRAS- CHAVE: Trabalho Pedagógico. Inclusão. Deficiência.

RESUMEN:El texto presenta una reflexión sobre los procesos inclusivos en la Educación Escolar y en la Universidad. Una cuestión orienta la investigación: ¿cómo se hace la inclusión de alumnos en la Enseñanza Media y en la Universidad? A partir de la complejidad del contexto social, ante la propuesta de la educación de calidad para todos, el texto tiene como objetivos levantar el debate sobre las posibilidades y

\footnotetext{
1 Universidade Estadual do Ceará- (UECE) - CE - Brasil. Professor da Educação Básica da Rede Estadual de Ensino do estado do Ceará. Mestre em Educação. E-mail: manoelpineo@ bol.com.br.

${ }^{2}$ Universidade Estadual do Ceará- (UECE) - CE - Brasil. Professora adjunta no Programa de Pósgraduação em Educação. Professora Visitante da Universidade da Integração Internacional da Lusofonia Afro - Brasileira- UNILAB. E-mail: azeriche@hotmail.com.

${ }^{3}$ Universidade Federal do Ceará (UFC) - CE - Brasil. Doutoranda no Programa de Pós-graduação em Educação Brasileira. Bolsista CAPES. E-mail: regianearaujjo@ hotmail.com
} 
límites de la educación de calidad para todos, hacer una revisión técnica que de subsidios para la discusión y reflexionar sobre El trabajo de los profesores de Educación Básica y de la Universidad ante los alumnos especiales en las aulas. Para ello, tuvimos como recurso metodológico la investigación bibliográfica y documental y diálogo con los profesores. Con el uso de autores como Aries (2013), Magalhães (2002), Minayo (2010), Pimenta (2014), Mantoan (2006), Dorziat (2011) entre otros, el texto apunta a la necesidad de efectivación de las políticas de inclusión $Y$ principalmente de las condiciones objetivas de trabajo y formación. Es necesario incentivo en la investigación y en los procesos formativos para la efectuación de las políticas de inclusión.

PALABRAS CLAVE: Trabajo pedagógico. Inclusión. Discapacidad.

ABSTRACT: The text presents a discussion on the inclusive processes in School Education and in the University. A question guides the research: how is the inclusion of students in High School and University? Starting from the complexity of the social context, in view of the proposal of quality education for all, the text aims to raise the debate about the possibilities and limits of quality education for all, to make a technical review that of subsidies for the discussion and to reflect on the work of the teachers of Elementary Education and of the University in front of the special students in the classrooms. For that, we had as a methodological resource bibliographical and documentary research and dialogue with teachers. With the use of authors such as Carneiro (2013), Magalhães (2002), Minayo (2010), Pimenta (2014), Mantoan (2006) and Dorziat (2011) among others, the text points to the need for effective inclusion policies and especially of the objective conditions of work and training. Incentives to research and training processes for the implementation of inclusion policies is needed.

KEYWORDS: Pedagogical work. Inclusion. Disability.

\section{Introdução}

Sabemos que a celeridade das transformações sociais chega ao campo da educação marcada por grandes desafios para o campo da formação. Esta reflexão se direciona às práticas de inclusão vivenciadas no interior das instituições de ensino médio e na universidade no contexto das propostas de "educação de qualidade para todos".

$\mathrm{O}$ atendimento dos alunos com deficiência, inseridos nas salas comuns ainda se depara com a falta de infraestrutura adequada dos espaços da escola regular, somada à preparação de professores para atender de maneira plena a permanência e a aprendizagem desses alunos. Contudo, o professor não tem a formação adequada para trabalhar com as especificidades dos alunos com deficiência, estando muitas vezes longe de possibilitar um atendimento satisfatório aos mesmos. De maneira igual, está 
distante a materialização do processo de ensino e aprendizagem que leva em consideração as diferenças, as dificuldades e as necessidades dos seus alunos.

Nesse sentido, indagamos: como a inclusão de alunos com deficiência vem sendo trabalhada no âmbito da escola de ensino regular? Como os professores vivenciam esta questão no ensino médio?

A escola, como instância educativa, precisa estar ciente de suas ações ajustando-se perante as diferentes demandas e exigências dos dias atuais, no sentido de oferecer um ensino que possa potencializar o processo de construção do conhecimento e o desenvolvimento de uma sociedade mais justa e qualitativamente melhor para todas as pessoas, pertencentes ao seu coletivo institucional. Sendo assim, este trabalho tem o objetivo de caracterizar as concepções de um grupo formado por três docentes de uma escola pública estadual, acerca da educação inclusiva, como estratégia de formação de alunos com deficiência inseridos nas classes comuns do ensino médio.

Uma segunda contribuição para o debate está direcionada aos processos inclusivos de alunos com deficiência na Universidade. Dessa forma, pretendemos refletir sobre a presença de alunos com deficiência no Estágio Curricular Supervisionado dos cursos de Licenciatura.

Levantar o debate sobre o tema é importante no sentido de alçar questões que possam viabilizar ações reflexivas capazes de redimensionar a caminhada da docência e da pesquisa na formação de professores no contexto em que estamos inseridos. Partimos das perguntas: Como a Educação Inclusiva é tratada na Universidade? Como esta mudança vem afetando a formação de novos professores?

O nosso objetivo é refletir sobre as mudanças, voltadas para a melhoria dos processos inclusivos de alunos com deficiência inseridos nas classes comuns dos estabelecimentos escolares de Ensino Médio e nos cursos de Licenciatura da Universidade. Assim, estaremos percorrendo a mesma temática em duas dimensões: as possibilidades de inclusão realizada no cotidiano das escolas e no Estágio Curricular Supervisionado, instigados pelos pontos de convergência que aproximam, ou afastam o tema nestes dois níveis de ensino - médio e o superior.

\section{Primeira reflexão: a escola de educação básica como espaço de inclusão}

Um dos grandes desafios do mundo atual diz respeito à implantação de uma escola inclusiva que busque o reconhecimento de todos os indivíduos e que seja capaz 
de difundir uma educação justa e de melhor qualidade. Confirmando essa visão, Mantoan (2006) acentua que a inclusão é, ao mesmo tempo, motivo e consequência de uma educação de qualidade que tem como compromisso a abertura para a diferenças. Dessa forma, as diferenças não podem se configurar como um problema, porquanto elas são elementos próprios da formação dos sujeitos e dos múltiplos contextos reais do cotidiano. Trata-se de uma quebra de paradigma, uma relação que exige novas maneiras de relacionamento e de formas de conduzir a vida da escola, o tratamento pedagógico entre professores e alunos em seus processos educativos, no tocante às formas de ensinar e de aprender.

De uma maneira geral, o modelo atual de educação escolar continua pautado na figura do professor como o transmissor dos conhecimentos socialmente construídos, na forte marca da homogeneização dos processos avaliativos. Os alunos são tratados como sujeitos, que aprendem na mesma cadência e suas especificidades e seus interesses não são vistos como pontos nevrálgicos do processo de ensino e da aprendizagem.

Complementando esta questão, Carneiro (2013), analisa o parágrafo primeiro do artigo 58 da Lei de Diretrizes e Bases da Educação Nacional, LDB nº. 9394, de 20 de dezembro de 1996, que disserta sobre os serviços especializados de apoio à escola regular no atendimento de alunos com necessidades educativas especiais ${ }^{4}$, destacando que estes serviços podem se desenvolver de diferentes maneiras:

Nas classes comuns: por meio da atuação de professores da educação especial, de docentes intérpretes das linguagens e códigos, além de profissionais de outras áreas (como da Fonoaudiologia, Psicologia, Medicina, Assistência social, dentre outras);

- Nos atendimentos itinerantes: por meio de equipes formadas por docentes especializados que se dirigem às escolas, para que, juntamente com os professores das classes comuns, possam complementar o atendimento educacional;

- No atendimento escolar hospitalar: por meio de docente especializado ou, de maneira eventual, que recebeu preparação para prestar atendimento ao aluno com deficiência que esteja hospitalizado, em estado interino ou contínuo;

- Nas salas de recurso: por meio de docente da educação especial ou em partilha com o pessoal de apoio de diferentes áreas, que disponibiliza um roteiro de

4 A expressão "necessidades educativas especiais" se refere às pessoas que apresentam deficiências, dificuldades de aprendizagem, problemas comportamentais, altas habilidades ou superdotação. (MAGALHÃES, 2002). 
atividades complementares e/ou suplementares ao currículo, empregando ferramentas e instrumentos específicos.

Como se observa, não é somente do professor da escola comum a responsabilidade pelos processos inclusivos dos alunos tidos como especiais. É preciso compreender estes indivíduos, rever o currículo escolar, garantir a presença contínua dos familiares e de profissionais especializados na escola para também mediar as ações, adequar os espaços escolares fisicamente, na perspectiva de propor novos mecanismos de aprendizagem e de permanência dos alunos com deficiência para que se sintam verdadeiramente como pessoas protagonistas do processo educativo e, mais que isso, seres atuantes da sociedade.

É indispensável também a criação de políticas públicas que amparem os professores das escolas comuns que, em muito, necessitam de conhecimentos para lidar com os processos inclusivos, oferecendo-lhes como, por exemplo, formações continuadas que instrumentalizem a sua prática, já que tanto se preconiza que as escolas devam se ajustar às peculiaridades e às potencialidades dos discentes.

A formação de professores para o contexto da sociedade atual precisa ser compreendida na complexidade do sistema educacional e na perspectiva interdisciplinar necessária à compreensão da realidade. Sobre esse tema, Minayo (2010) propõe a seguinte reflexão:

O que tem a ver a interdisciplinaridade com a complexidade? É imprescindível o pensamento complexo para definirmos o objeto, e para buscarmos seu rumo e sua compreensão interdisciplinar. Mas a interdisciplinaridade não configura uma teoria específica: ela é uma estratégia. O conhecimento se constrói com uma visão complexa de um investigador ou uma rede de pesquisadores (MINAYO, 2010, p. 441)

Assim, a autora nos indica a pesquisa dos fenômenos educativos, como ponto de partida para a construção do conhecimento que possa fundamentar ações pedagógicas, capazes de apontar para as posturas emancipadoras e de visão da totalidade social.

\section{É possível uma formação de professores "para todos"?}

O trabalho do professor, no tocante aos fenômenos do ensinar e do aprender sofre uma multiplicidade de interferências advindas da própria organicidade das 
instituições, na sua relação com o contexto mais amplo. Lima (2015) considera a questão da Didática na sua condição de campo de conhecimento que se constitui como área de ampliação natural dos assuntos pedagógicos, no âmbito da elaboração do conhecimento e de aquisição de saberes que ocorrem no contexto das instituições educativas e, mais notadamente, nas situações reais das salas de aulas.

Charlot (2002) chama atenção para os desafios de materialização das reflexões sobre a relação entre teoria e prática e, ainda, sobre as possibilidades de a pesquisa em educação entrar na sala de aula, apontando que o professor está exposto a emergências que precisa resolver no dia a dia da docência e, desse modo, não resta à este profissional o tempo e as condições objetivas suficientes para refletir. Assim, Charlot (2002, p. 91) aponta que "O papel da pesquisa é forjar instrumentos, ferramentas para melhor entender o que está acontecendo na sala de aula; é criar intelegibilidade para melhor entender o que está acontecendo ali".

De acordo com Zeichner (1992), as posturas metodológicas reflexivas devem considerar que a prática reflexiva deve se concentrar nos professores, levando em consideração tanto o exercício profissional como as condições sociais em que ocorre; a compreensão de que os atos dos docentes são políticos e que devem direcionar-se a objetivos de natureza emancipatória; o reconhecimento da dimensão coletiva da prática reflexiva enquanto prática social, apontando para a necessidade de que as escolas se constituam como comunidades de aprendizagem.

Pimenta (2014) constata que na educação escolar a expansão quantitativa dos sistemas de ensino não vem correspondendo a um resultado de qualidade que se adeque às exigências das pessoas envolvidas, nem tampouco às necessidades pertinentes às demandas sociais, o que torna importante a definição de uma nova identidade da profissão docente. É preciso, no entanto, viabilizar o desenvolvimento de um trabalho de boa qualidade que não está ligado apenas a questões do "como fazer", já que este depende de um processo reflexivo que une um conjunto de ações sociais e políticas. Há um equívoco em se pensar os procedimentos metodológicos como instrumentos capazes de resolver os males que afligem os espaços escolares ou mesmo como aparato meramente técnico-instrumental. É preciso pensá-los a partir de bases para a edificação dos conhecimentos e das transformações das situações pertinentes ao processo educativo. Mediante este panorama, Candau (2013, p. 94) afirma que a natureza multidimensional e contextualizada dos procedimentos didáticos exige um contínuo repensar pedagógico à luz dos novos desafios que a sociedade e a educação apresentam 
para a construção de uma escola democrática e de uma cidadania plena, consciente e crítica". Portanto, o professor necessita equilibrar a sua prática tanto em termos técnicos quanto pedagógicos, visando a ampliação de espaços democráticos e colaborativos, a emancipação humana e a construção de um processo ininterrupto pela melhoria da qualidade da educação de todos os indivíduos.

\section{Escola: um espaço favorável à inclusão?}

Um dos grandes desafios da atualidade diz respeito à implantação de uma escola inclusiva, que procure acompanhar as necessidades sociais sem perder a capacidade de refletir sobre as contradições em que está inserida.

De maneira geral, o modelo atual de educação escolar continua pautado na figura do professor como o transmissor dos conhecimentos socialmente construídos, na forte marca da homogeneização dos processos avaliativos. Nessa visão, os alunos são tratados como sujeitos que aprendem na mesma cadência, cujas especificidades e interesses não são vistos como pontos nevrálgicos do processo de ensino e da aprendizagem. Recorremos a Mantoan (2006) para nos apoiar e explicar o que em parte dificulta o estabelecimento da inclusão escolar,

$\mathrm{Na}$ verdade, resiste-se à inclusão escolar porque ela nos faz lembrar que temos uma dívida a saldar em relação aos alunos que excluímos pelos motivos mais banais e inconsistentes, apoiados por uma organização pedagógico-escolar, que se destina a alunos ideais, padronizados por uma concepção de normalidade e de eficiência arbitrariamente definida (MANTOAN, 2006, p. 25).

Como se observa, não é somente do professor da escola a responsabilidade pelos processos inclusivos dos alunos tidos como especiais. É preciso compreender estes alunos para poder efetuar as mudanças necessárias quanto ao currículo escolar, a presença dos familiares e de profissionais especializados na organização coletiva da escola, para mediar as ações, adequar os espaços físicos da escola, na perspectiva de propor novos mecanismos de aprendizagem e de permanência dos alunos com deficiência.

É indispensável também a defesa de políticas e ações que amparem os professores das escolas comuns que, em muito, necessitam de conhecimentos para lidar com os processos inclusivos, oferecendo-lhes formação continuada que instrumentalizem a sua prática e valorizem as potencialidades dos discentes. Sobre 
formação de professores e inclusão nos espaços institucionais de ensino, Dorziat (2011, p.154) expressa a necessidade de maior aprofundamento e adequação às necessidades pedagógicas e operacionais de alunos e professores:

Se as formações de professores continuarem trabalhando numa ótica desenvolvimentista, psicologizante, de enquadramento dos alunos a modelos pré-determinados, a currículos engessados e veiculadores de relações assimétricas, a inclusão continuará se processando apenas como uma possibilidade humana na diversidade.

Ademais, não há perspectiva de modificar as práticas dos docentes sem que estes tenham a compreensão de suas razões e benefícios, em prol dos discentes, da escola, do sistema de ensino e do seu desenvolvimento profissional. (PRIETO, 2006).

Fica evidente a complexidade do sistema educacional com todas as suas nuanças e desafios na construção de um cenário escolar inclusivo. Em vista disso, é preciso reconhecer que sem o envolvimento do coletivo institucional e da comunidade escolar: docentes, alunos, família, gestores, funcionários da comunidade local e demais constituintes da sociedade, qualquer ideia de formulação e/ou reformulação voltadas para a melhoria da escola não terá, de fato, o resultado almejado.

\section{Experiência docente sobre a inclusão de alunos no Ensino Médio}

Para conversar com os professores de uma Escola de Ensino Médio de Fortaleza, estabelecemos um diálogo com quatro docentes que tinham em suas salas de aula, a presença de alunos com deficiência. Como complemento, pedimos que estes profissionais elencassem as principais dificuldades enfrentadas por eles no convívio com esta mudança no seu trabalho. Os argumentos formulados em resposta à referida questão enfatizavam aspectos que iam desde a falta de preparação docente até a falta de infraestrutura e de materiais didáticos nas escolas que pudessem, de fato, viabilizar o atendimento e o acesso, com frequência, dos alunos com deficiência,

\footnotetext{
Por sinal percebe-se um aumento desse número a cada ano. Eu tenho inúmeras dificuldades em lidar com essa realidade, principalmente, em como obter um desempenho satisfatório em relação ao aprendizado. Percebo que existe uma boa aceitação, um excelente relacionamento entre alunos com deficiência e os demais colegas, porém acho que o desenvolvimento intelectual é deixado de lado como se somente a interação fosse o suficiente. (P1)
} 
Vejo duas grandes dificuldades. Primeiro é a questão da acessibilidade do aluno portador de deficiência física, ou seja, a falta de rampas, elevadores etc. Isso dificulta o acesso desse aluno ao ambiente escolar. Segundo grande problema seria a falta total de qualificação do quadro de professores. (P2)

Atualmente tenho alunos com graus diversos de déficit de aprendizagem; problemas auditivos; problemas psíquicos [...]. São muitas as dificuldades; não sei libras [...]; ao identificar o déficit de aprendizagem não sei o que fazer. (P3)

Uma dificuldade maior que enfrentamos é sobre o material didático, pois ele não vem adaptado para o aluno e de apoio pedagógico. ( $\mathrm{P} 4)$

Analisando as palavras dos professores do Ensino Médio quando ao destacarem que "o desenvolvimento intelectual é deixado de lado como se somente a interação fosse o suficiente" sinaliza para o fato de que a escola de ensino regular está longe de conduzir práticas educativas que promovam significado à vida dos alunos com deficiência. Na mesma medida, soa como indício de denúncia a constatação de que a promoção escolar desses alunos vem sendo realizada de forma automática. Sobre essa questão, concordamos com Mantoan (2006, p. 54-55) quando explica a complexidade dessa inclusão que requer um novo projeto de educação,

Ensinar, na perspectiva inclusiva, significa ressignificar o papel do professor, da escola, da educação e de práticas pedagógicas que são usuais no contexto excludente do nosso ensino, em todos os seus níveis. A inclusão escolar não cabe em um paradigma tradicional de educação e, assim sendo, uma preparação do professor nessa direção requer um design diferente das propostas de profissionalização existentes e de uma formação em serviço que também muda, porque as escolas não serão mais as mesmas, se abraçarem esse novo projeto educacional.

O autor contribui nessa reflexão reiterando que não basta apenas colocar o aluno com deficiência no meio de outros considerados "normais". É necessário incluí-lo na escola promovendo as adequações necessárias às suas especificidades, às suas diferenças, agindo didaticamente na perspectiva da construção de um espaço propício ao aprendizado desse indivíduo.

Quando perguntamos aos docentes sobre seus entendimentos pessoais por educação inclusiva, todas as falas convergiram no sentido de que a mesma está direcionada para o atendimento dos discentes com necessidades educacionais especiais. 
Sendo assim, frisamos o depoimento de P1 para sintetizar as expressões de todos os respondentes da pesquisa com relação à referida questão,

Educação inclusiva é caracterizada pela inclusão dos portadores de necessidades especiais ou de distúrbios de aprendizagem na rede comum de ensino. É aquela em que mesmo com todos os obstáculos que o aluno possa enfrentar, consequente de sua deficiência, ele possa obter algum tipo de avanço em relação ao processo de ensino, pois não basta haver somente interação física, deve existir um meio propício para que o desenvolvimento aconteça. Portanto, educação inclusiva vai além do que receber o aluno na rede comum, é saber trabalhar com as dificuldades contando com todos os recursos necessários. (P1)

É preciso, além das mudanças de ordem pedagógica e administrativa tão enfatizadas no discurso das mudanças, que ocorra a implantação de políticas públicas e ações voltadas para os processos inclusivos, tanto de alunos como de professores. Requer um olhar introspectivo de respeito e dignidade à todos os integrantes da escola.

Os professores que estão à frente das salas de aula se veem solitários diante do fenômeno da inclusão de alunos com necessidades especiais, pois precisam de assistência, de um grupo de apoio e de estudo, que fortaleça seus modos de conceber e intervir no sistema educativo.

Lutar pela inclusão nas instituições escolares vai muito mais além, é uma tarefa de todos, isto é, um compromisso coletivo da sociedade que deve ser permeado pelo respeito às diferenças e pela compreensão de que as pessoas com necessidades educativas especiais também têm o direito de vez e voz como qualquer outro cidadão.

É preciso considerar que a falta de condições e de profissionais que possam subsidiar o atendimento aos educandos com deficiência, bem como o número excedente de alunos por sala de aula, acaba por inviabilizar um acompanhamento do projeto de inclusão. Dorziat (2011) lembra que a indefinição do papel do docente para a inclusão pode decorrer de uma formação docente de abordagem sistêmica que abre espaço para uma postura de abertura às singularidades humanas na experiência prática.

\section{Segunda reflexão: por uma universidade inclusiva?}

Sabemos que um número crescente de alunos com necessidades especiais, ingressa na Universidade, no entanto, pouco se sabe como estes alunos chegam ao final do curso. Nesse contexto, a reflexão de Naujorks (2009) nos mostra que a Universidade, 
na condição de instituição social, vivencia suas contradições, conflitos, confrontos de ideias e assim, nem sempre chega a atender, a contento, a demanda da sociedade, mesmo ciente de seu papel social,

\begin{abstract}
Suas ações, muitas vezes, são balizadas por dois polos: o primeiro garante a conservação e manutenção do conhecimento; dificulta a ruptura com o instituído e mantém a "viscosidade" das estruturas acarretando uma lentidão nas tomadas de decisão. O segundo promove o progresso por meio da investigação de novos paradigmas, busca alternativas que venham ao encontro de políticas claras, consistentes, objetivas, concretizando-se em mudança, impulsionando o conhecimento e o desenvolvimento. (NAUJORKS, 2009, p. 243).
\end{abstract}

O autor enfatiza a dualidade existente entre os avanços e o conservadorismo das Universidade enquanto instituição social. Dessa forma, ao mesmo tempo busca de alternativas de desenvolvimento, situa-se no movimento dialético e contraditório de mudança e resistência aos novos paradigmas, assim convivendo com a morosidade de alternativas de consolidação das mudanças.

Contribuindo nessa discussão, Magalhães (2006), afirma que o ensino superior no Brasil se revela como um capítulo marcado pela exclusão de uma considerável parcela de pessoas à educação. A autora destaca que a gênese das universidades brasileiras aconteceu de modo tardio em razão do processo de colonização, isto é, houve resistência por parte de Portugal pela instauração de instituições universitárias no Brasil. Tal atitude fez o povo brasileiro, mesmo no momento ulterior à independência, considerar de pouca valia a implantação de universidades em âmbito nacional, detendose, assim, às classes abastadas brasileiras, o privilégio de enviar seus filhos para a Europa visando à formação superior.

A formação em nível superior, sobretudo as licenciaturas, implica uma formação teórica articulada ao desenvolvimento de atividades práticas, por meio do Estágio Supervisionado, como componente curricular obrigatório, constituindo-se este em um valioso espaço para o aluno compreender o ambiente escolar e construir uma gama de conhecimentos teóricos e práticos que possibilitem à busca por resultados positivos ao processo educacional como um todo.

\title{
Seria o estágio um espaço de inclusão?
}


O Estágio Supervisionado, parte obrigatória do Projeto Político Pedagógico dos cursos de formação docente, tem sido alvo de inúmeras críticas em relação à existência de um desencontro entre as bases teóricas e a prática educacional. Mais ainda, com raras exceções, chega a não ser levado à sério pelas pessoas e instâncias envolvidas, desvelando-se, dessa maneira, como uma atividade fragilizada para o exercício de aprendizagem e aprimoramento da docência,

O professor que orienta nem sempre consegue romper com as supostas amarras dos projetos pedagógicos dos cursos de formação de professores, ou mesmo convencer os seus pares da necessidade de mudanças; muitos pares da universidade ainda tratam estágio ora como sobrecarga, peso e castigo, ora como trabalho fácil, sem status de disciplina, como mero processo de orientação, como se orientação não fosse igualmente atividade docente que exige preparação, planejamento, avaliação e muita dedicação (PARENTE; MATTOS, 2015, p. 67).

As considerações das autoras nos permitem deduzir que um Estágio poderá deixar marcas na vida dos futuros docentes, uma vez que não garante o real entendimento do que venha a ser a profissão de professor e o contexto escolar com todas as suas diversidades, contingências e possibilidades. Desse modo, é necessário que haja a manifestação efetiva dos membros envolvidos no decurso formativo dessa disciplina, isto é, deve ser firmado o compromisso efetivo entre a universidade e a instituição de ensino básico, a fim de redimensionar os conteúdos e metodologias de ensino adotadas no Estágio, adequando-os à atual realidade.

Em sua análise, Lima e Costa (2014) distinguem o Estágio a partir de duas perspectivas. A primeira se refere ao Estágio como o momento de colocar em prática as lições recebidas, ou ainda como oportunidade de adquirir conhecimento para atuação no espaço da sala de aula. A segunda diz respeito ao Estágio desenvolvido em conexão com atividades que indiquem o respeito à memória docente, a criatividade e ao diálogo como fundamento, metodologia e práxis. Dessa forma, a coleta de dados acerca das instituições escolares e do corpo docente se efetivaram em forma de reflexão nos seminários, narrativas e memórias sobre o itinerário escolar como instrumento de formação inicial e contínua.

A compreensão do lugar do magistério na história de vida do licenciando, o conhecimento do corpo docente das escolas, bem como o entendimento do que vem a ser a profissão de professor compõem três aspectos fundamentais a serem considerados 
no estudo do Estágio Supervisionado no processo de formação dos futuros docentes, como nos ensina Lima (2012).

Valentini e Bisol (2012) destacam que para a implantação de um processo inclusivo de alunos com necessidades educacionais especiais, a instituição universitária vai precisar se defrontar com uma sucessão de situações desafiadoras. Fazem parte da convivência com tais situação as atitudes de colaboração, inclusão, decisão compartilhada e respeito às diferenças, entre outras.

\section{Conversa com docentes que lecionam a disciplina: estágio supervisionado}

Os professores com quem conversamos lecionam em uma das Universidades, situada no município de Fortaleza, expressaram diferentes abordagens a respeito dos poucos alunos portadores de deficiência que chegavam ao final do curso para cursar as disciplinas de Estágio Supervisionado. Uns descreveram os problemas enfrentados, enquanto outros disseram do interesse em resolver as dificuldades, dentro das suas próprias possibilidades e limitações. Diante da pergunta "como é realizado o Estágio dos alunos com deficiência?”, obtivemos as seguintes respostas:

Chegou um aluno que era deficiente visual, então eu enviava todo o material digitalizado para ele e nos reuníamos sempre na Universidade pós-encontro nas escolas, para tirarmos dúvidas. Ele ministrou o Estágio junto com outro colega e eu assisti a uma aula ministrada por ele. O aluno demonstrou bastante autonomia no desenvolvimento da sua aula e os alunos pareciam participar mais, por ficarem curiosos como ele conseguia superar a sua deficiência visual e fazer uma Faculdade (Professora A).

Um aluno teve dificuldade com a Escola na disciplina de Estágio I, foi rejeitado, mas a coordenadora de área mostrou-se comovida porque houve boa aceitação dele junto aos alunos. Comprometeu-se de acompanhá-lo mais de perto e ajudá-lo para obter essa experiência. Foi adaptado para aulas de reforço escolar (Professora B).

No Estágio tive um aluno que tinha dificuldade de interação e de atenção. De fato eu tinha que repetir todas as informações que eram pontuais, como prazos e orientações básicas de Estágio, pois ele não conseguia anotar à medida que escutava. Tentei escrever tudo na lousa, mas, mesmo assim, ele sentia a necessidade de perguntar várias vezes cada informação como uma forma de validar sua compreensão. (Professora C). 
Importante verificar que as tentativas não envolvem o coletivo institucional e parecem ser encaminhadas em um processo de desvinculação com o projeto de formação do curso. Também há relato de sinais de dificuldade com relação à interação com a classe e com a disciplina. Sobre estas questões Moreira (2005) explica que, embora o ingresso dos estudantes com necessidades educacionais especiais simbolize um avanço nesse contexto, é necessária ainda a realização de muito trabalho voltado para a busca de novas conquistas. Assim, para um processo inclusivo efetivo não basta apenas garantir a admissão desses alunos na educação superior, mas possibilitar também meios eficientes para a sua permanência com qualidade. Para tanto, é preciso tomar como ponto de referência as suas características e potencialidades, dando-lhes as condições necessárias para a sua aprendizagem e crescimento tanto pessoal quanto profissional.

A responsabilidade fica nas mãos da professora de Estágio que, em contato com a coordenação, o professor e os alunos da escola recebedora, passa a lidar com dificuldades para as quais não está preparada. Assim, situações de rejeição e estigma sofrido pelos alunos e pelo corpo docente da escola, não são questionadas como fenômenos que carecem de estudos e pesquisas. Nesse aspecto, Magalhães (2002) afirma que a pessoa, ao se desviar da norma, passa a ser rotulada e estigmatizada. A autora explica que a significância do vocábulo estigma é marca e está relacionada ao descrédito social vivida pela pessoa que foge da "normalidade", o que leva a julgamentos das pessoas com relação aos desviantes e neste caso, os desviantes são as pessoas com deficiência. Neste caso, o aluno com deficiência ao chegar à escola de educação básica para realizar o Estágio pode se deparar com olhares preconceituosos do corpo docente, ou parte dele, sobre sua condição ou comportamento.

A preocupação com o processo a inclusão do estudante com deficiência no decurso do Estágio, continua a requerer da professora, o exercício de trabalho extra, para digitalizar e fazer a orientação do estagiário na Universidade. Nessa direção, Araújo (2016) aponta que é papel do supervisor fazer o acompanhamento e a organização do processo formativo do estagiário, colocando-se à disposição para apoiálo no percurso de formação. Assim, é preciso que o professor da Disciplina de Estágio Supervisionado, também cognominado de supervisor ou orientador do Estágio, desenvolva um trabalho pedagógico procurando atender as expectativas e necessidades dos estagiários. 
A disciplina Estágio Curricular Supervisionado alia aprendizagem de conhecimentos da teoria pedagógica com e o desenvolvimento de capacidades de ordem prática visando a práxis, proveniente da indissolubilidade teoria e prática. No entanto, é preciso considerar as condições de vida e trabalho do professor de Estágio no contexto das políticas de formação de professores.

\section{Considerações finais}

Os estudos sobre a inclusão nos mostram a longa distância que existe entre o direito do aluno com deficiência e a realidade que requer a compreensão dessa estrada a ser percorrida entre os processos democráticos previstos no discurso da inclusão e a realidade da prática do contexto institucional e curricular da Escola e da Universidade.

A realidade dos alunos com deficiência no cenário da educação superior deve exceder a mera inserção física desses estudantes em seus espaços de ensino dentro das suas diferenças e especificidades, bem como o aprendizado necessário para que possam finalizar com sucesso seus estudos em nível de graduação.

Promover práticas inclusivas no Estágio requer que o professor supervisor esteja comprometido em promover a inclusão no cotidiano de suas atividades de sala de aula. No entanto, não podemos transferir a responsabilidade de forma exclusiva aos professores, uma vez que a inclusão requer amplo debate, reflexões e posicionamentos comprometidos de todos os partícipes da instituição e da sociedade. Do mesmo modo, as leis existentes são suficientes para a consolidação de um projeto de educação inclusiva no âmbito da universidade, se não houver a devida cobrança de todos para a efetividade de suas aplicabilidades.

A Universidade precisa se legitimar como espaço inclusivo dos alunos com deficiência, para além das atividades de ensino, alcançando plenamente a pesquisa e a extensão, inseridas no interior do Projeto de Universidade e das suas ações estratégicas.

Dessa forma, compreendemos que o estudante com deficiência que chega à universidade, apesar dos seus problemas e dificuldades enfrentadas, possui capacidade e potencial para progredir muito mais ainda em seus estudos. Cabe, portanto, à comunidade acadêmica colaborar para a melhoria do convívio desse aluno não somente no espaço da academia, mas também nos diferentes espaços da vida social. Já no espaço escolar, os processos de inclusão requerem, além da participação das pessoas e instituições incumbidas pelo seu desenvolvimento, ser legitimado como espaço 
inclusivo no processo formativo docente dos alunos com deficiência, possibilitando à estas atividades condizentes às suas especificidades e particularidades, incluindo o fomento de suas aptidões e habilidades.

Acreditamos que a partir dos caminhos percorridos e análises empreendidas, novos estudos poderão surgir sob outros prismas e outras perspectivas. Cabe, portanto, a todos nós, tratar a questão como objeto de pesquisa a ser explorada nos Programas de Pós-Graduação e na Iniciação Científica. Igualmente, se faz necessário, que os cursos de formação docente, passem a visualizar melhor as questões formativas decorrentes da Educação Inclusiva, não apenas como disciplina isolada, mas no contexto da profissão Magistério e da sociedade, como um todo.

\section{REFERÊNCIAS}

ARAUJO, R. D. de. O acompanhamento do estágio supervisionado na formação docente: concepções e condições de trabalho dos supervisores. 1 ed. Curitiba, PR: CRV, 2016.

BRASIL. Ministério da Educação. Lei de Diretrizes e Bases da Educação Nacional. Lei no 9394/96. Estabelece as diretrizes e bases da educação nacional. Brasília, 20 de dezembro de 1996. Disponível em:

<http://www.planalto.gov.br/ccivil_03/Leis/L9394.htm>. Acesso em: 06 ago. 2017.

CARNEIRO, M. A LDB Fácil, Leitura Crítico Compreensiva Artigo a Artigo. 20. ed. Petrópolis RJ: Editora Vozes, 2013.

CANDAU, V. M. (Org). Rumo uma nova didática. 23. ed. Petrópolis, RJ: Vozes, 2013.

CHARLOT, B. Formação de professores: a pesquisa e a política educacional. In: PIMENTA, S. G.; GHEDIN, E. Professor reflexivo no Brasil: gênese e crítica de um conceito. São Paulo: Cortez, 2002.

DORZIAT, A. A formação de professores e a educação inclusiva: desafios contemporâneos. In: CAIADO, K. R. M.; JESUS, D. M. de.; BAPTISTA, C. R. (Orgs.). Professores e educação especial: formação em foco. Porto Alegre:

Mediação/CDV/FACITEC, 2011, p. 147-159.

LIMA, M. S. L.; NASCIMENTO, A. M. do. As raízes do Estágio Curricular Supervisionado: fundamentos que sustentam suas práticas. In: ALBUQUERQUE, J. V. de.; MOTA NETO, J. C. da.; OLANDA, O. F. J.; RIBEIRO, W. de O. (Orgs.). O estágio na formação do pedagogo: reflexões e vivências. Belém: EDUEPA, 2015, p. 19-38. 
LIMA, M. S. L.; NASCIMENTO, A. M. do. Estágio e aprendizagem da profissão docente. Brasília: Liber Livro, 2012.

LIMA, M. S. L.; NASCIMENTO, A. M. do; COSTA, E. A. da S. A formação do professor para o trabalho em Educação de Jovens e Adultos: lições do estágio curricular supervisionado. In: ALMEIDA, M. I. de.; PIMENTA, S. G. (Orgs.). Estágios

supervisionados na formação docente: educação básica e educação de jovens e adultos. São Paulo: Cortez, 2014. p. 41-67.

MAGALHÃES, R. de C. B. P. Ensino superior no Brasil e inclusão de alunos com deficiência. In: VALDÉS, M. T. M. (Org.). Inclusão de pessoas com deficiência no ensino superior no Brasil: caminhos e desafios. Fortaleza: EDUECE, 2006, p. 39-55.

MAGALHÃES, R. de C. B. P. Traduções para as palavras diferença/deficiência: um convite à descoberta. In: MAGALHÃES, R. de C. B. P. (Org.). Reflexões sobre a diferença: uma introdução à educação especial. Fortaleza: Edições Demócrito Rocha, 2002, p. 21-34, 112.

MINAYO, M. C de S. Disciplinaridade, interdisciplinaridade e complexidade. Emancipação, Ponta Grossa, v. 10, n. 2, p. 435-442, 2010.

MOREIRA, C. L. In(ex)clusão na universidade: o aluno com necessidades educacionais especiais em questão. Revista Educação Especial, n. 25, 2005, p. 1-6.

NAUJORKS, M. I. A pesquisa em educação especial na Universidade Federal de Santa Maria. In: JESUS, D. M. de.; BAPTISTA, C. R.; BARRETO, M. A. S. C.; VICTOR, S. L. (Orgs.). Inclusão, práticas pedagógicas e trajetórias de pesquisa. 2.ed. Porto Alegre: Mediação, 2009. p. 243-248.

MATTOS, M. J. V. M. de. O estágio supervisionado na formação dos profissionais da educação. In: PARENTE, C. da M. D.; VALLE, L. E. L. R. do.; MATTOS, M. J. V. M. de. (Orgs.). A formação de professores e seus desafios frente às mudanças sociais, políticas e tecnológicas. Porto Alegre: Penso, 2015.

PIMENTA, S. G (orgs.). Estágios supervisionados na formação docente: educação básica e educação de jovens e adultos. São Paulo: Cortez, 2014.

PRIETO, R. G. Atendimento escolar de alunos com necessidades educacionais especiais: um olhar sobre as políticas públicas de educação no Brasil. In: MANTOAN, M. T. E. Inclusão escolar: pontos e contrapontos. Mantoan, M. T. E., Prieto, R. G.; Arantes, V. A. (Org.). São Paulo: Summus, 2006.

VALENTINI, C. B.; BISOL, C. A. Inclusão no Ensino Superior: especificidades da prática docente com estudantes surdos. Caxias do Sul, RS: Educs, 2012.

ZEICHNER, K. Novos caminhos para o practicum: uma perspectiva para os anos 90. In: NÓVOA, A. (Org.) Os Professores e a sua Formação, p. 115-138, Lisboa: Pub. Dom Quixote. 1992. 


\section{Como referenciar este artigo}

SOUSA, Manoel Pinéo de.; LIMA, Maria Socorro Lucena.; ARAÚJO, Regiane Rodrigues. Entre a exigência de qualidade no trabalho pedagógico e a inclusão de alunos com deficiência no ensino médio e na universidade. Revista on line de Política e Gestão Educacional, Araraquara, v. 21, n. esp. 2, p. 946-963, nov. 2017. Disponível em: <http://dx.doi.org/10.22633/rpge.v21.n.esp2.2017.10371>. ISSN: 1519-9029.

Submetido em: 05/09/2017

Aprovado em: 21/09/2017 